\title{
Chalcopyrite and Molybdenite Flotation in Seawater: The Use of Inorganic Dispersants to Reduce the Depressing Effects of Micas
}

\author{
Rodrigo Yepsen ${ }^{1,2}\left(\mathbb{D}\right.$, Joaquín Roa ${ }^{1,2}$, Pedro G. Toledo ${ }^{1,3}$ and Leopoldo Gutiérrez ${ }^{1,2, *(D)}$ \\ 1 Water Research Center for Agriculture and Mining (CRHIAM), Universidad de Concepción, \\ Concepción 4070411, Chile; rodrigoyepsen@udec.cl (R.Y.); joaroacabrera@gmail.com (J.R.); \\ petoledo@udec.cl (P.G.T.) \\ 2 Department of Metallurgical Engineering, Universidad de Concepción, Concepción 4070371, Chile \\ 3 Department of Chemical Engineering, Universidad de Concepción, Concepción 4070371, Chile \\ * Correspondence: lgutierrezb@udec.cl
}

Citation: Yepsen, R.; Roa, J.; Toledo, P.G.; Gutiérrez, L. Chalcopyrite and Molybdenite Flotation in Seawater: The Use of Inorganic Dispersants to Reduce the Depressing Effects of Micas. Minerals 2021, 11, 539. https://doi.org/10.3390/min11050539

Academic Editor: Przemyslaw

B. Kowalczuk

Received: 23 April 2021

Accepted: 17 May 2021

Published: 19 May 2021

Publisher's Note: MDPI stays neutral with regard to jurisdictional claims in published maps and institutional affiliations.

Copyright: (c) 2021 by the authors. Licensee MDPI, Basel, Switzerland. This article is an open access article distributed under the terms and conditions of the Creative Commons Attribution (CC BY) license (https:/ / creativecommons.org/licenses/by/ $4.0 /)$.

\begin{abstract}
The objective of this work was to study the effect of muscovite and biotite on the flotation of chalcopyrite and molybdenite in seawater, and the use of sodium hexametaphosphate and sodium silicate to improve copper and molybdenum recoveries. The impact of the inorganic dispersants on the settling properties of the resulting flotation tailings was also studied. It was found that muscovite and biotite depress the flotation of chalcopyrite and molybdenite in seawater, with this depressing effect being stronger at $\mathrm{pH} 11$ than at $\mathrm{pH}$ 9. Sodium hexametaphosphate and sodium silicate increased the recoveries of copper and molybdenum in seawater. These dispersants render the mineral particles more negatively charged and remove the hydroxy-complexes of magnesium and calcium from the mineral particles causing dispersion of the slimes. The settling rates of the flotation tailings slightly decrease when sodium hexametaphosphate and sodium silicate were added in the flotation stage. The presence of ultrafine particles dispersed by the action of the inorganic dispersants negatively impacted the flocculation and sedimentation processes leading to high flocculant consumption, low settling rates and high turbidity of the supernatant.
\end{abstract}

Keywords: seawater flotation; inorganic dispersants; micas; chalcopyrite; molybdenite

\section{Introduction}

Processing of low-grade ores rich in phyllosilicates is becoming more common in copper-molybdenum flotation plants [1]. These gangue species get dispersed in suspension as ultra-fine particles, modifying the rheological behavior of mineral suspensions and negatively affecting the efficiency of the process through several mechanisms $[2,3]$. Phyllosilicates are classified into four groups, i.e., serpentines, clay minerals, micas, and chlorites [4], of which those of the clay and mica groups are usually found in copper/molybdenum ores [5]. Previous studies reported the depressing effect of clay minerals, such as kaolinite and smectites, on the flotation of metal sulfides, such as chalcopyrite and molybdenite [2,6-9]. An interesting case study is flotation in seawater because it was reported that the depressing effect of clay minerals becomes stronger in this aqueous medium [7].

Micas such as muscovite and biotite are phyllosilicates usually found in complex copper ores. Muscovite is one of the most common micas that occurs in various environments with a general formula being $\mathrm{KAl}_{2}\left(\mathrm{AlSi}_{3} \mathrm{O}_{10}\right)(\mathrm{OH})_{2}$. The monoclinic crystal structure of muscovite consists of tetrahedral sheets bonded together by interchanging layers of $\mathrm{K}^{+}$ and octahedral $\mathrm{Al}^{+3}[10,11]$. In muscovite, $25 \%$ of the tetrahedral sites are occupied by $\mathrm{Al}$ and $75 \%$ by Si, isomorphous substitution represents the primary source of its negative surface charge [12]. Fine-grained white mica, such as muscovite, is usually found in copper ores, such as those treated in the Chuquicamata Concentrator of CODELCO-Chile, 
and it is usually referred to as sericite. Biotite is an important trioctahedral mica with a composition varying between phlogopite, the Mg-rich end member, and the annite, the Fe-rich member [12]. Its approximate chemical formula is $\mathrm{K}(\mathrm{Mg}, \mathrm{Fe})_{3} \mathrm{AlSi}_{3} \mathrm{O}_{10}(\mathrm{~F}, \mathrm{OH})_{2}$ and it is sometimes referred to as dark mica. Previous studies reported that the isoelectric point of biotite is at $\mathrm{pH} \mathrm{3.0,} \mathrm{and} \mathrm{from} \mathrm{batch} \mathrm{potentiometric} \mathrm{titrations,} \mathrm{the} \mathrm{point} \mathrm{of} \mathrm{zero}$ charge is around 9.66. Of course, the large differences can be related to the anisotropic character of this mica mineral [13]. The depressing effect of clay minerals on the flotation of chalcopyrite and molybdenite becomes stronger in the presence of most of the cations in seawater [7-9]. These cations induce a certain degree of hydrophilicity on these minerals, which leads to low recoveries at $\mathrm{pH}>9.5$ even in the absence of clay minerals, due to the depressant effect of hydroxy complexes of $\mathrm{Ca}$ and $\mathrm{Mg}$, which precipitate as $\mathrm{Ca}(\mathrm{OH})_{2}$ and $\mathrm{Mg}(\mathrm{OH})_{2}$ on mineral surfaces [14-17]. Hydrolyzed species of divalent cations $(\mathrm{Ca}, \mathrm{Mg})$ induce heterocoagulation between clay mineral particles and metal sulfides which explains the poor flotation efficiency [7]. The use of dispersants to remove precipitated/coagulated hydrolyzed species from molybdenite surfaces was previously tested [18] and it was demonstrated that sodium hexametaphosphate (SHMP) restores molybdenite flotation at $\mathrm{pH}>$ 9.5. It was also shown [8] that SHMP and sodium silicate (SS) improved copper flotation in seawater by dispersing kaolinite particles from the chalcopyrite surfaces. However, the depressing effect of micas on the flotation of chalcopyrite and molybdenite in seawater and how dispersants such as SHMP and SS affect these results need more attention. The impact of these dispersants on the resulting flotation tailings' settling properties is something that also deserves further study.

This work aims to study the effect of muscovite and biotite on the flotation of chalcopyrite and molybdenite in seawater, and the use of SHMP and SS to improve copper and molybdenum recoveries. The impact of SHMP and SS on the settling properties of the resulting flotation tailings is also studied.

\section{Materials and Methods}

\subsection{Samples and Reagents}

Ward's Natural Science Establishment provided samples of highly pure muscovite and biotite, which were manually dry ground to $-2 \mathrm{~mm}$ and kept in sealed plastic bags. A chalcopyrite sample was prepared from mineralized rock specimens, provided by Ward's Natural Science Establishment. The XRD chalcopyrite content of the sample was $99 \%$ with minor amounts of quartz $(0.7 \%)$ and pyrite $(0.3 \%)$. The chemical analysis of the samples indicated $34.5 \% \mathrm{Cu}, 30.0 \% \mathrm{Fe}$, and $35.5 \% \mathrm{~S}$. A sample of molybdenite $(-88+44 \mu \mathrm{m})$ was obtained from a molybdenum concentrate. This latter sample was washed using acetone and $\mathrm{NaSH}$ to remove collectors and other organic compounds and then cleaned through three stages of collector-less flotation to remove contaminants. The effectiveness of the cleaning procedure was verified by measuring the total organic carbon (TOC) content of the liquid extracts at different $\mathrm{pHs}$. The results showed zero TOC values, indicating the absence of flotation reagents in the molybdenite sample [1]. The chemical analysis of the molybdenite sample ( 99.8\% molybdenite) indicated a composition of $0.35 \% \mathrm{Cu}, 0.20 \% \mathrm{Fe}$, $38.1 \%$ S, $59.8 \% \mathrm{Mo}$, and $1.55 \%$ of non-soluble minerals.

Potassium amyl xanthate (PAX), and thiocarbamate from Solvay were used as collectors, and methyl isobutyl carbinol (MIBC) and $\mathrm{NaCl}$ obtained from Merck (Santiago, Chile), respectively, as frother and supporting electrolyte. Distilled water with an electrical conductivity of $10 \mu \mathrm{S} / \mathrm{cm}$ was used to prepare solutions when needed. $\mathrm{pH}$ was adjusted using lime in all the tests. SHMP obtained from Sigma Aldrich (Providencia, Chile) (97\% purity) and SS from Millipore Sigma as an extra pure solution $\left(\mathrm{SiO}_{2} / \mathrm{Na}_{2} \mathrm{O}=3.3\right)$ were used as dispersants. Seawater from the coast of the Bíobío Region was used, the chemical composition is detailed in Table 1. 
Table 1. Concentration of ionic species in seawater from the coast of the BíoBío Region in Chile [19].

\begin{tabular}{cc}
\hline Element & Concentration, $\mathbf{~ g / L}$ \\
\hline $\mathrm{Cl}^{-}$ & 19,345 \\
$\mathrm{Na}^{+}$ & 10,752 \\
$\mathrm{SO}_{4}^{2-}$ & 2701 \\
$\mathrm{Mg}^{2+}$ & 1295 \\
$\mathrm{Ca}^{2+}$ & 416 \\
$\mathrm{~K}^{+}$ & 390 \\
$\mathrm{HCO}_{3}^{-}$ & 154 \\
$\mathrm{Br}^{-}$ & 66 \\
$\mathrm{BO}_{3}{ }^{3-}$ & 27 \\
$\mathrm{Sr}^{2+}$ & 13 \\
$\mathrm{~F}^{-}$ & 1 \\
$\mathrm{Others}^{-}$ & $<1$ \\
\hline
\end{tabular}

\subsection{Procedures}

Batch flotation tests were carried out in a $2.7 \mathrm{~L}$ automated flotation machine (EDEMET). The flotation feed corresponded to $1 \mathrm{~kg}$ of artificial $\mathrm{Cu}-\mathrm{Mo}$ ore $(1 \% \mathrm{Cu}, 0.02 \% \mathrm{Mo})$ prepared by mixing chalcopyrite, molybdenite, and quartz or micas. In the tests with micas, quartz was substituted by either muscovite or biotite. The mica contents considered were 7 and $15 \%$ by mass. The artificial ore was first crushed in a cone crusher to a particle size of $-2 \mathrm{~mm}$, and then wet ground using carbon steel balls as grinding media to obtain a P80 of 150 micrometers in a laboratory ball mill at $67 \%$ solids content. Table 2 shows the percentages of particles in the -38 micrometers size fraction of the flotation feed. Mineral slurries were then poured into the flotation cell and seawater was added to get a solid content of $32 \%$. The $\mathrm{pH}$ was measured using an $\mathrm{Ag} / \mathrm{AgCl}$ electrode BELL-EP24 and adjusted to 9 or 11 with lime, with seawater consumption of $3.6 \mathrm{~g} / \mathrm{kg}$ to reach $\mathrm{pH} 9$, and $9.4 \mathrm{~g} / \mathrm{kg}$ to reach $\mathrm{pH} 11$. The lime consumption increased around $1.1 \%$ as the mica content in the artificial ore increased 1 percentage point. SHMP or SS were added ( 3 dosages of 0.5 , 2.0 , and $3.0 \mathrm{~kg} / \mathrm{t}$ ), and then the slurries were conditioned for $2 \mathrm{~min}$ at $900 \mathrm{rpm}$ with $40 \mathrm{~g} / \mathrm{t}$ $\mathrm{PAX}, 40 \mathrm{ppm}$ thiocarbamate, and $20 \mathrm{ppm}$ MIBC. The airflow rate was $12 \mathrm{~L} / \mathrm{min}$, and the concentrates were collected every $10 \mathrm{~s}$ for $10 \mathrm{~min}$. Froth was controlled and fixed at $1.5 \mathrm{~cm}$ height. Concentrates and tailings were analyzed for copper and molybdenum to determine recoveries and grades. All tests were performed in triplicate to quantify the reproducibility of the experiments, and the error bars associated with every data point are included in the plots, with the bar width representing one standard deviation.

Table 2. Percentage of particles in the -38 micrometers size fraction of the flotation feed.

\begin{tabular}{cccc}
\hline Muscovite, $\boldsymbol{\%}$ & $\mathbf{\% - 3 8} \boldsymbol{\mu \mathbf { m }}$ & Biotite, $\mathbf{\%}$ & $\mathbf{\% - 3 8} \boldsymbol{\mu \mathbf { m }}$ \\
\hline 0 & 38 & 0 & 38 \\
7 & 41 & 7 & 40 \\
15 & 42 & 15 & 43 \\
\hline
\end{tabular}

To understand the effect caused by SHMP and SS on the electrophoretic mobility of chalcopyrite and mica particles, measurements were carried out using a Zetacompact $\mathrm{Z} 9000$ from CAD instruments. Suspensions were prepared by mixing $0.07 \mathrm{~g}$ of fine particles ( -20 micrometers) with calcium and magnesium solutions. Suspensions were conditioned for $3 \mathrm{~min}$ under magnetic agitation. As the ions in the solutions strongly compressed the electrical double layer and neutralized the charges on the particle surfaces, it was important to keep the ionic strength to a minimum so that the calcium and magnesium concentrations were established at $0.05 \mathrm{~mol} / \mathrm{L}$. Sodium hydroxide was used instead of lime as a $\mathrm{pH}$ modifier in these tests to avoid divalent calcium ions, which have a stronger effect on increasing the ionic strength of the medium than monovalent sodium ion. Some experiments using a $0.01 \mathrm{M} \mathrm{NaCl}$ solution were also carried out. 
The influence of SHMP and SS added in the flotation stage on the resulting tailings' settling properties was assessed by settling tests in a $2 \mathrm{~L}$ glass cylinder using the flocculant CYFLOC A-150 HW in dosages of 8,20 and $50 \mathrm{~g} / \mathrm{t}$. The tailings suspensions were homogenized for $15 \mathrm{~s}$ in the cylinder after which the position of the pulp-liquid interface was measured as a function of time for $30 \mathrm{~min}$, and the settling rate was obtained from the slope of the initial linear section of the curve. Turbidity measurements of the supernatant samples taken after 6 min of settling were taken using a HACH $2100 \mathrm{~N}$ turbidimeter.

\section{Results}

\subsection{Flotation Results}

Figure 1 shows copper and molybdenum recoveries and concentrate grades as a function of mica content at $\mathrm{pH} 9$ and 11 , in fresh water (a $0.01 \mathrm{M} \mathrm{NaCl}$ solution) and seawater. The results in seawater (Figure 1a,b) indicate that the presence of micas, either muscovite or biotite, reduce the recovery of copper and molybdenum, and that this depressing effect is stronger at $\mathrm{pH} 11$. The experimental results also show that the copper and molybdenum concentrate grades decrease as the mica content increases which can be explained by the reduction in flotation of fully liberated particles of chalcopyrite and molybdenite. In the absence of micas, molybdenite flotation is strongly reduced in seawater at $\mathrm{pH} 11$, which agrees with previous studies [18]. Figure 1c,d also indicates that the depressing effect of micas on copper and molybdenum recovery in fresh water is minor.
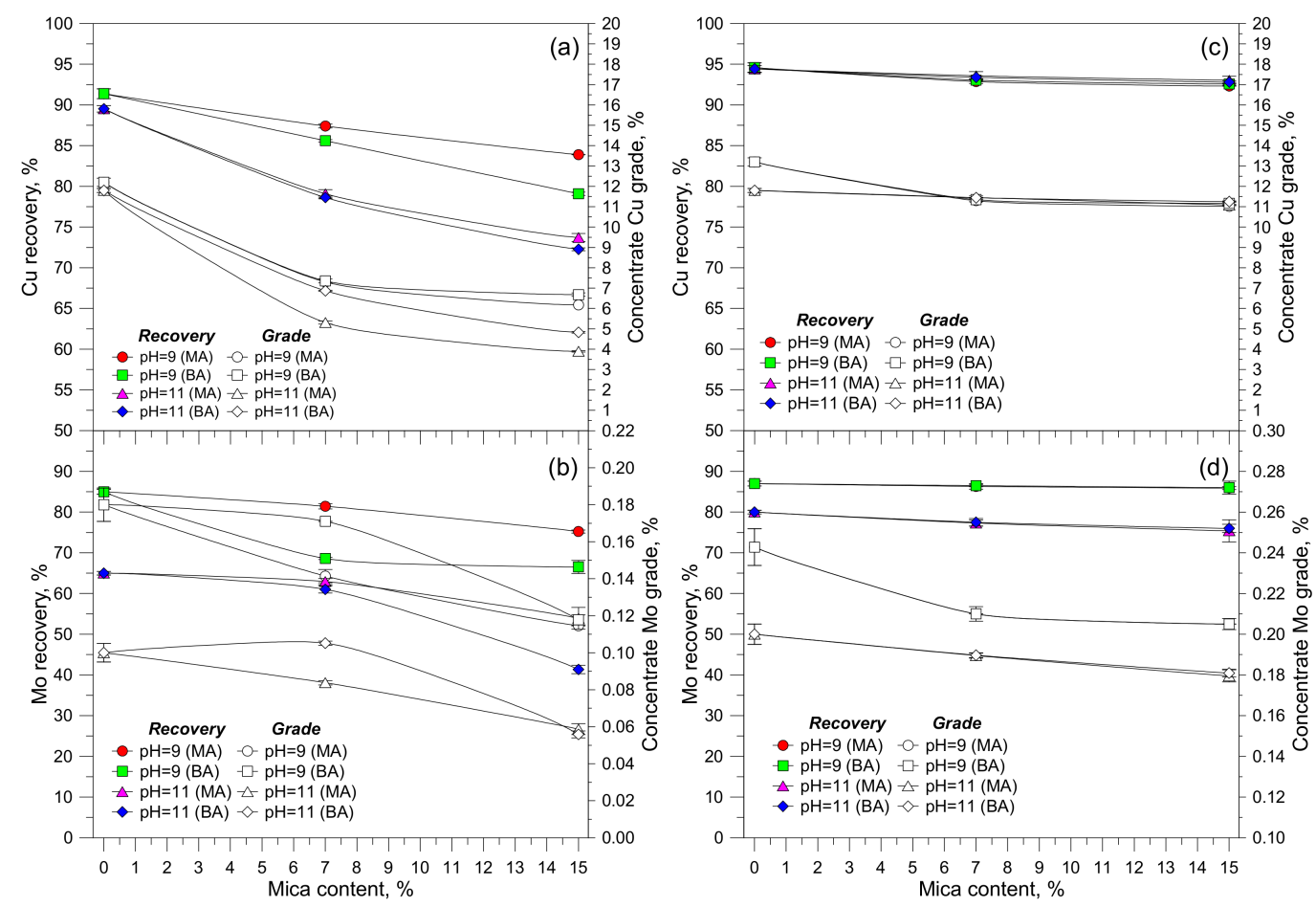

Figure 1. Recoveries and concentrate grades of copper and molybdenum as a function of mica content at $\mathrm{pH} 9$ and 11 in seawater $(\mathbf{a}, \mathbf{b})$, and in a $0.01 \mathrm{M} \mathrm{NaCl}$ solution $(\mathbf{c}, \mathbf{d})$. MA and BA stand for muscovite and biotite additions, respectively.

Figure 2 shows the recoveries of copper (Figure 2a,b) and molybdenum (Figure 2c,d) in seawater at $\mathrm{pH} 9$ and 11 as a function of SHMP and SS dosages, and two muscovite contents. With dispersant, the recoveries of copper and molybdenum reach values similar to those in the absence of micas. The positive effect of SHMP tends to be slightly better than that of SS at high muscovite contents and $\mathrm{pH}$ 11. Figure 3 shows that the concentrate grades follow an inverse relationship with the mass pull, which explains why the increase in recoveries observed in Figure 2 does not necessarily produce higher grades of concentrates since this parameter also depends on the mass of concentrates. 
Figure 4 presents the recoveries of copper (Figure 4a,b) and molybdenum (Figure 2c,d), and the concentrates grades in seawater as a function of SHMP and SS dosages, and two biotite contents. Again, dispersants increase the recoveries of copper and molybdenum, and the positive effect of SHMP is slightly better than that of SS. Figure 5 shows that the copper and molybdenum grades in the concentrates follow an inverse relationship with the mass pull, as in the muscovite experiments.
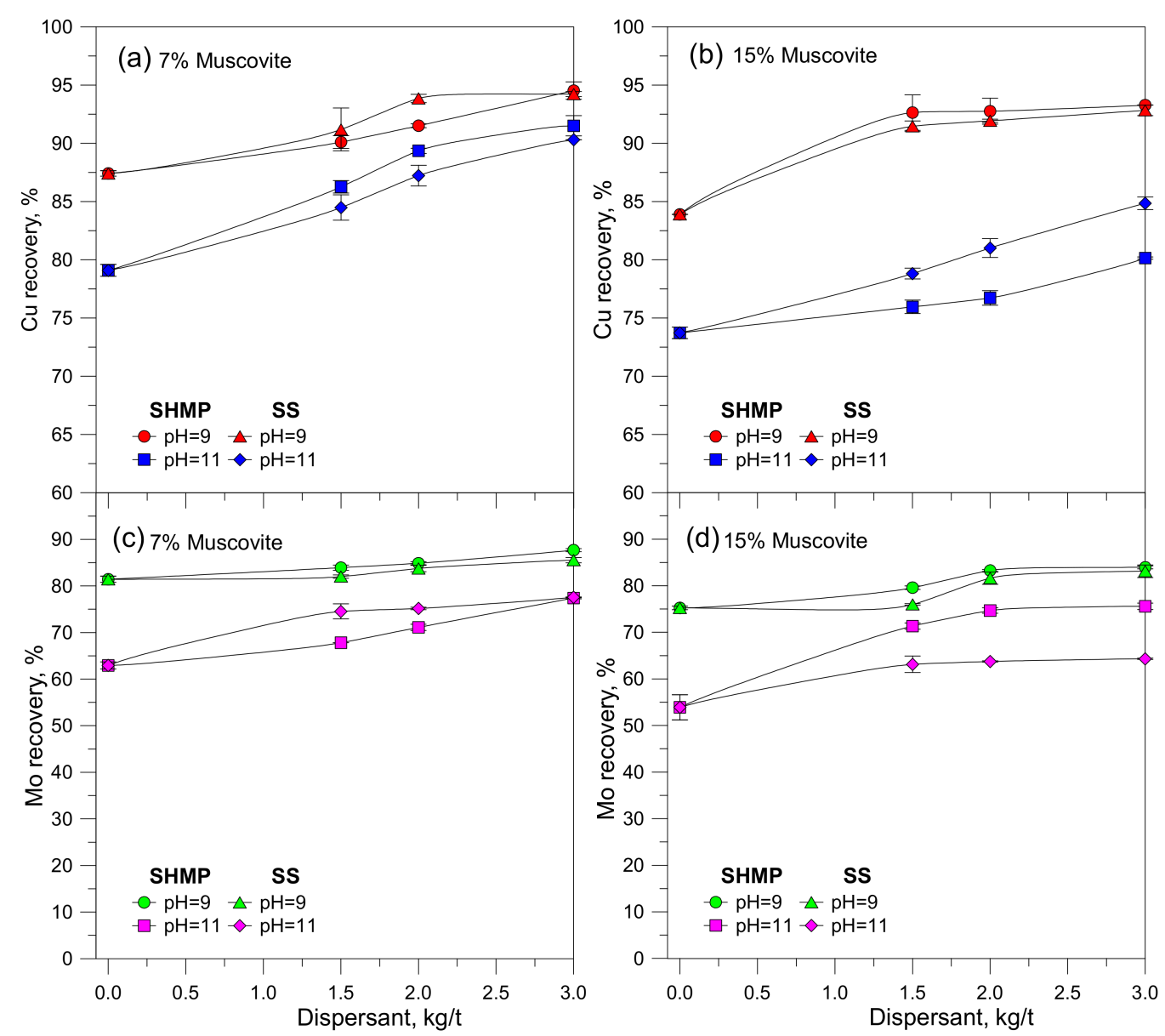

Figure 2. Copper $(\mathbf{a}, \mathbf{b})$ and molybdenum $(\mathbf{c}, \mathbf{d})$ recoveries in seawater at $\mathrm{pH} 9$ and 11 , as a function of dispersant dosage (SHMP, SS), and two muscovite contents. 

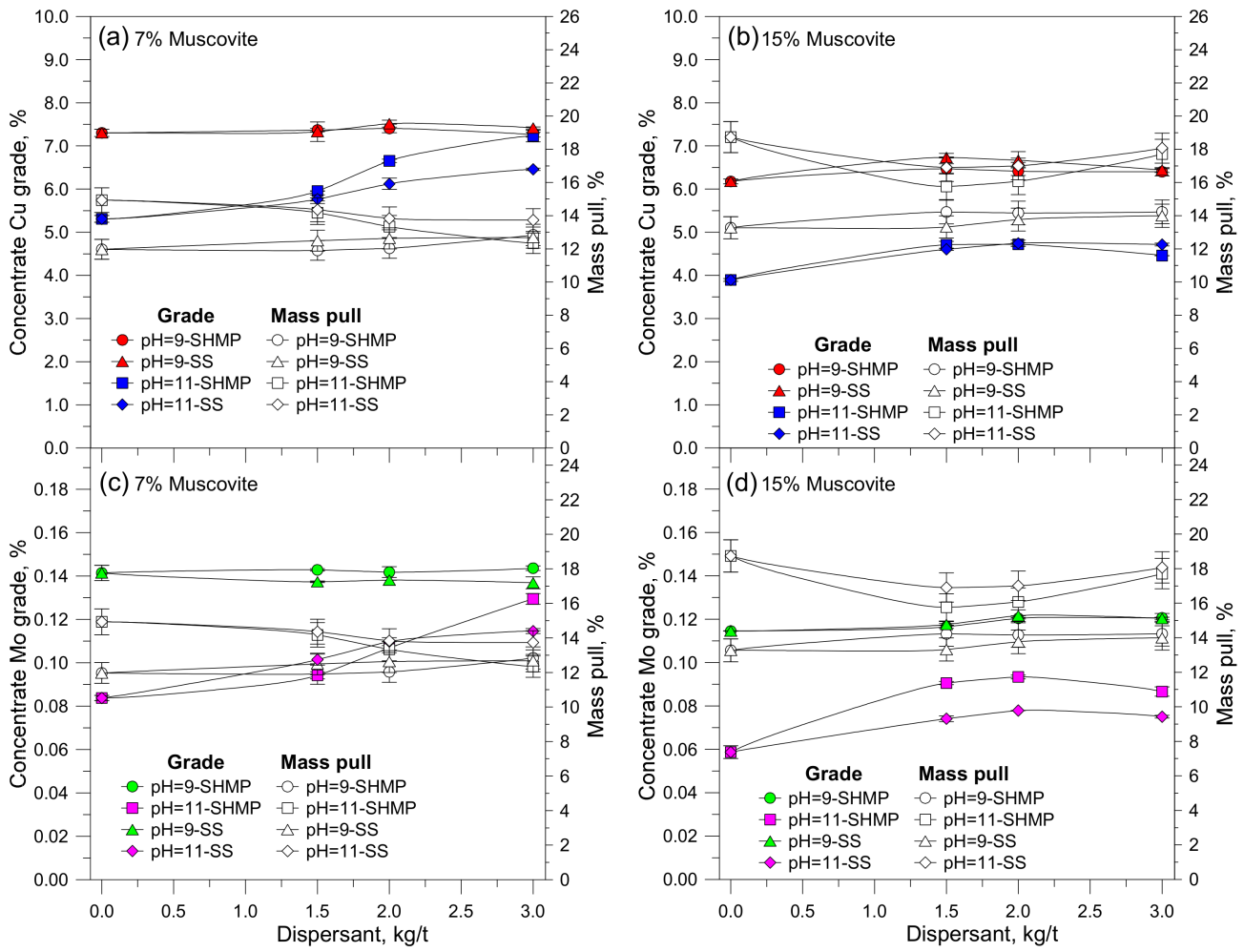

Figure 3. Copper $(\mathbf{a}, \mathbf{b})$ and molybdenum $(\mathbf{c}, \mathbf{d})$ concentrate grades and mass pull in seawater at $\mathrm{pH} 9$ and 11, as a function of dispersant dosage (SHMP, SS), and two muscovite contents.
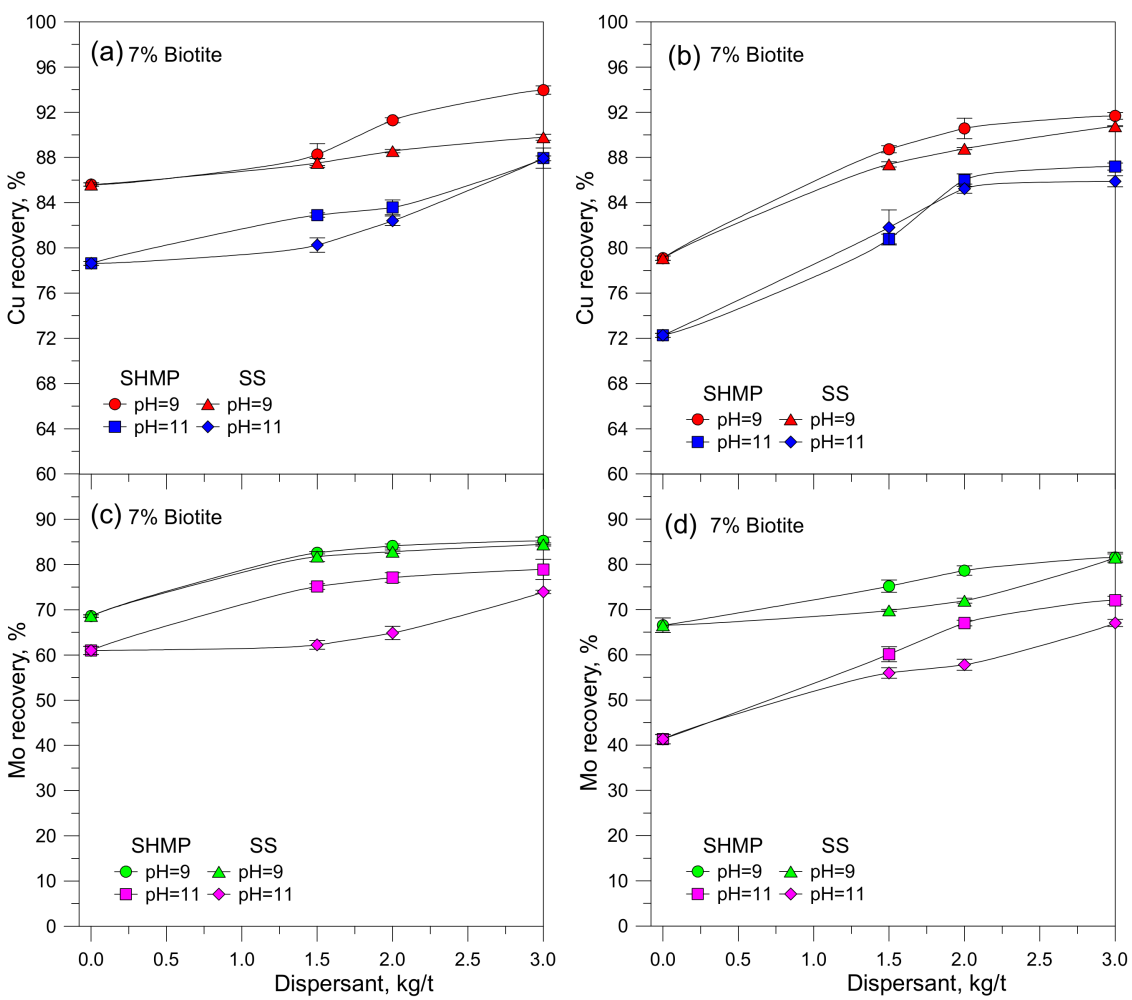

Figure 4. Copper $(\mathbf{a}, \mathbf{b})$ and molybdenum $(\mathbf{c}, \mathbf{d})$ recoveries and concentrate grades in seawater at $\mathrm{pH} 9$ and 11, as a function of dispersant dosages (SHMP, SS), and two biotite contents. 

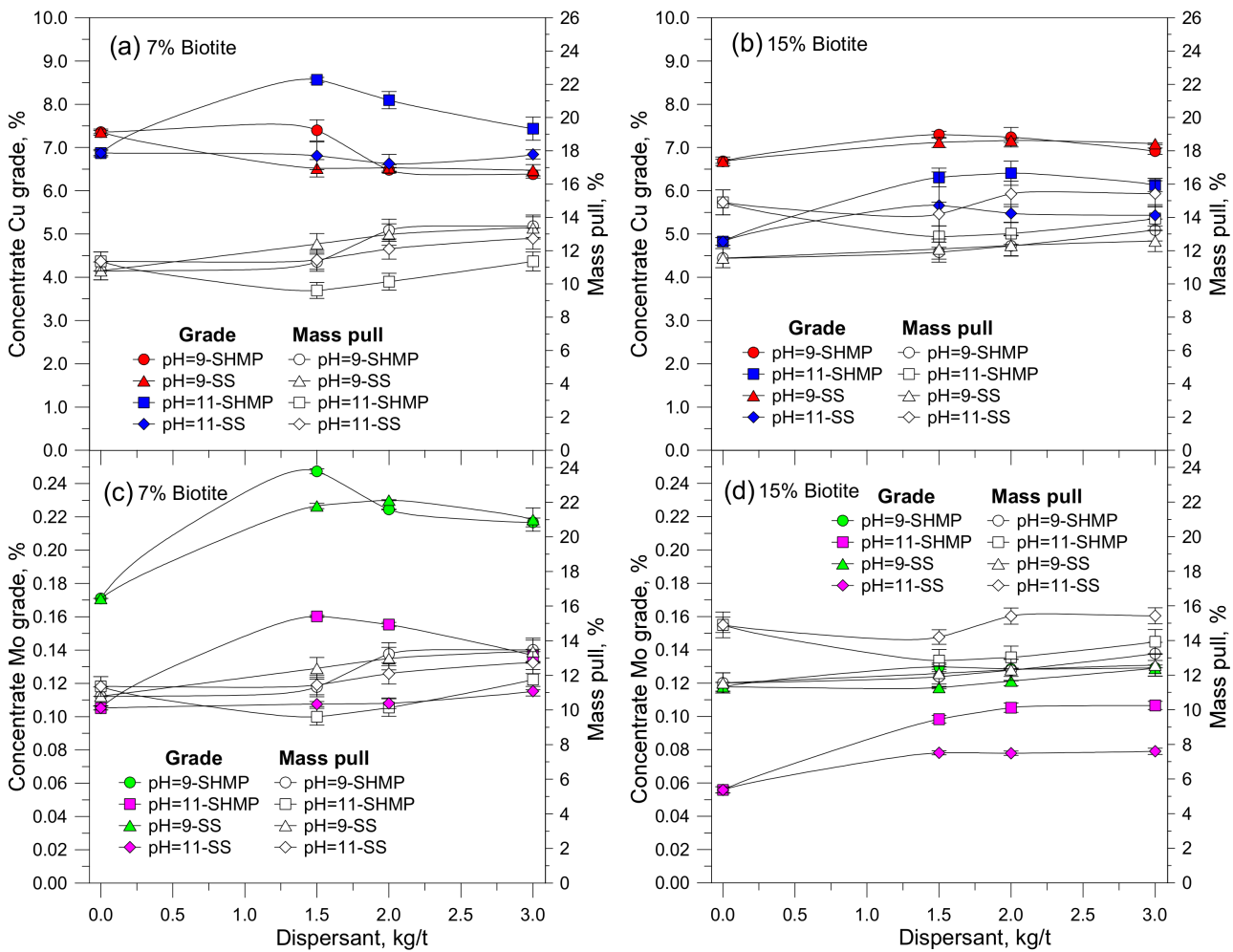

Figure 5. Copper $(\mathbf{a}, \mathbf{b})$ and molybdenum $(\mathbf{c}, \mathbf{d})$ concentrate grades and mass pull in seawater at $\mathrm{pH} 9$ and 11 , as a function of dispersant dosage (SHMP, SS) and two biotite contents.

\subsection{Electrophoretic Mobility}

Figure 6 shows the electrophoretic mobility distributions of biotite (Figure $6 \mathrm{a}, \mathrm{b}$ ) and muscovite Figure $6 \mathrm{c}, \mathrm{d}$ ) particles, with and without SHMP, in aqueous solutions of magnesium and calcium at pH 9 and 11. In this study, electrophoretic mobility measurements, rather than zeta potential, are used to describe the surface properties of muscovite and biotite, since these particles are markedly anisotropic with faces and edges, both carrying different surface properties and surface charge. Therefore, using the Smoluchowski equation to calculate the zeta potential is inappropriate [13]. The results obtained in the absence of SHMP show that the electrophoretic mobilities shift to less negative values as $\mathrm{pH}$ increases from 9 to 11 with magnesium causing the strongest shift. The colloidal magnesium hydroxide precipitates that appears at $\mathrm{pH}>9.5$ [20] block the anionic sites on the mica particles, deactivating them. Molecular simulation was recently used to understand the interaction of precipitates of magnesium hydroxide complexes with quartz, kaolinite, and also polymer flocculants [21]. The effect of calcium is less pronounced than the effect of magnesium because the concentration of solid precipitates of calcium is significant at $\mathrm{pH}$ values higher than 11. Figure 6 shows that the addition of SHMP shifts the electrophoretic mobility to more negative values, indicating that this reagent effectively disperses the magnesium and calcium precipitates from the mica particle surfaces.

Figure 7 shows the electrophoretic mobility distributions of muscovite (Figure 7a,b) and biotite (Figure $7 \mathrm{c}, \mathrm{d}$ ) particles, with and without $\mathrm{SS}$, in aqueous magnesium and calcium solutions at $\mathrm{pH} 9$ and 11. These results also indicate that SS shifts the electrophoretic mobility to more negative values, indicating the dispersion of precipitates from the mica surfaces. The effect of SS is slightly weaker than the effect of SHMP. 

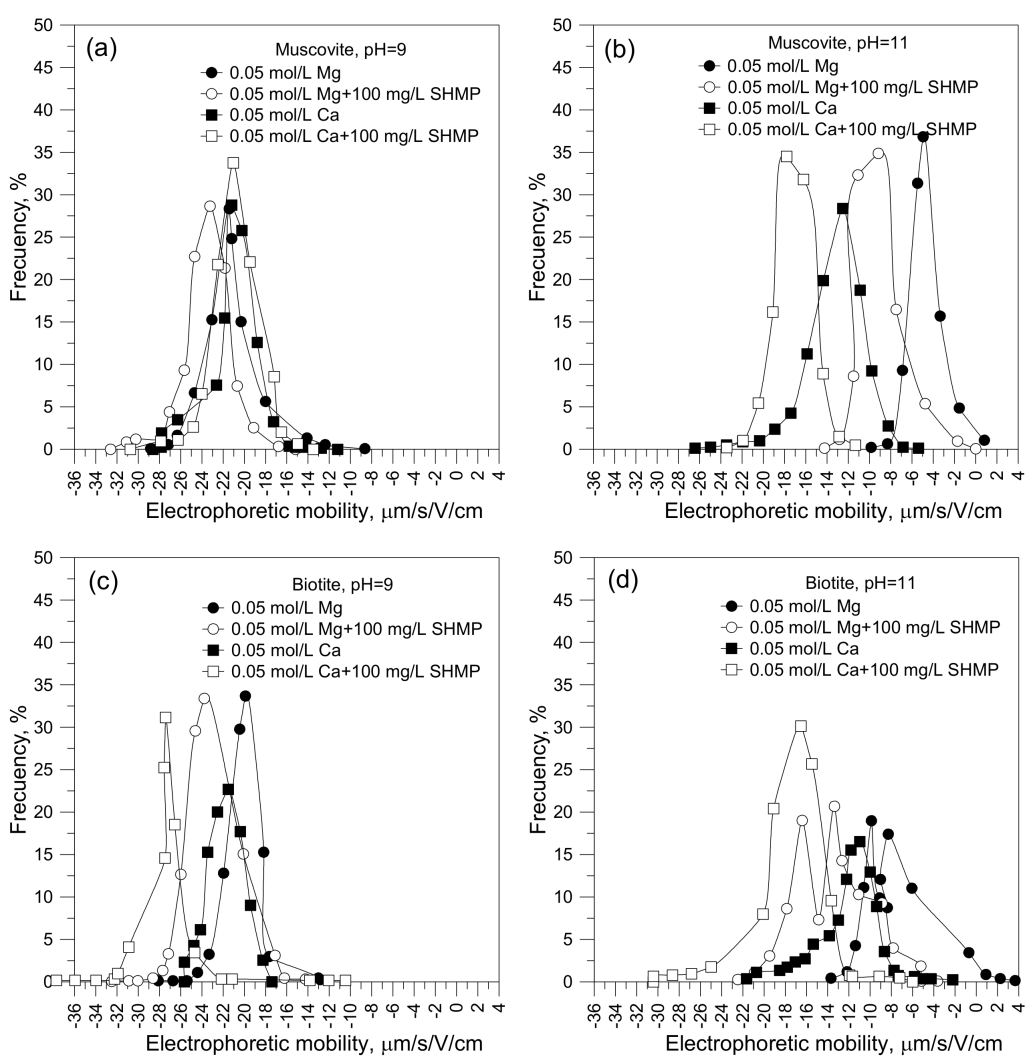

Figure 6. Electrophoretic mobility distributions of particles of muscovite (a,b) and biotite (c,d), with and without SHMP, in aqueous solutions of magnesium and calcium, and at $\mathrm{pH} 9$ and 11.
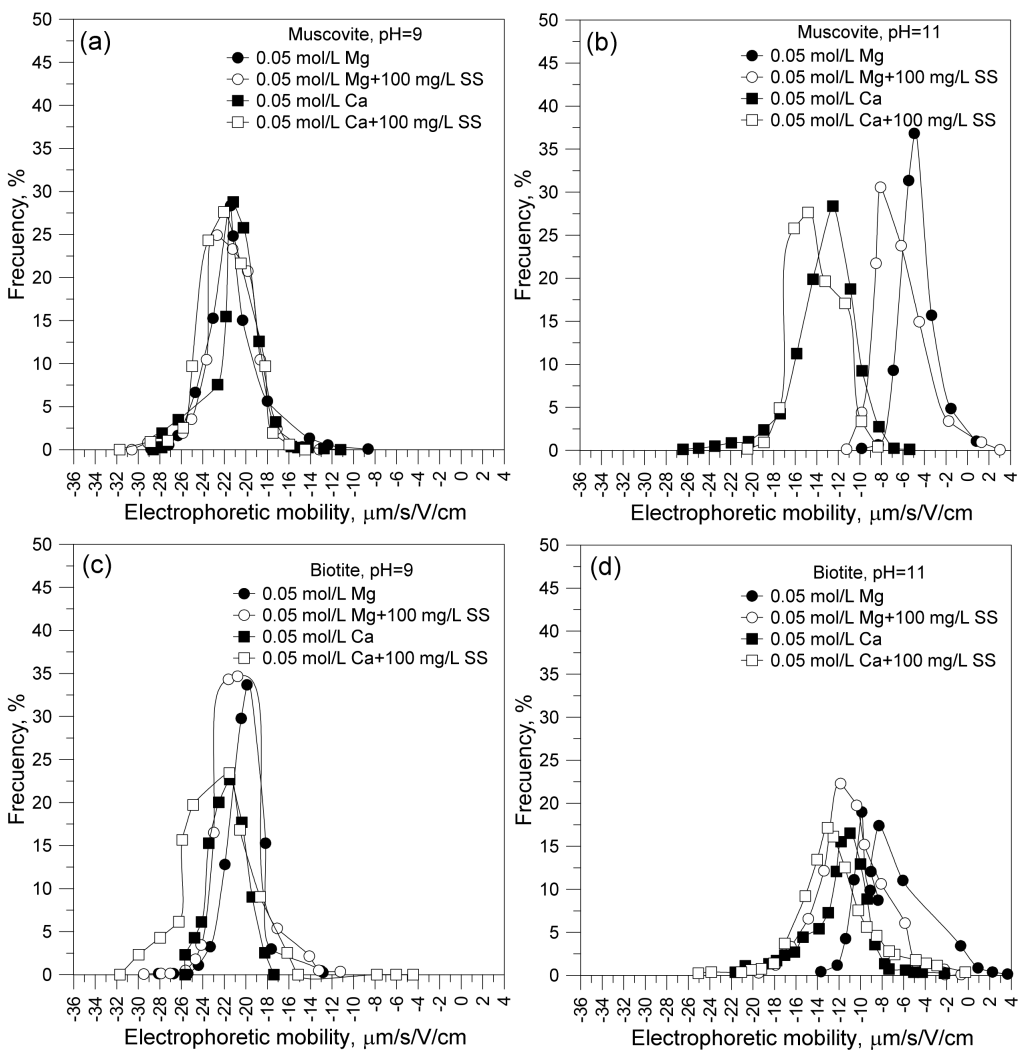

Figure 7. Electrophoretic mobility distributions of particles of biotite $(\mathbf{a}, \mathbf{b})$ and muscovite $(\mathbf{c}, \mathbf{d})$, with and without SS, in aqueous solutions of magnesium and calcium, and at $\mathrm{pH} 9$ and 11. 
The flotation results indicate that micas depress chalcopyrite and molybdenite, and that the use of dispersants SHMP and SS restore the flotation of these metal sulfides. Table 3 shows the effect of SHMP and SS on the zeta potential of chalcopyrite in aqueous solutions of magnesium and calcium, at pH 9 and 11. It can be seen that these dispersants also shift the zeta potential of chalcopyrite to more negative values, in particular at $\mathrm{pH}=11$, which is evidence of the dispersion of magnesium precipitates from the chalcopyrite surfaces. Previous studies also show that SHMP and SS disperse magnesium hydroxy complexes from the molybdenite surface $[9,18]$.

Table 3. Effect of SHMP and SS on the zeta potential of chalcopyrite $(\mathrm{mV})$ in aqueous solutions of magnesium and calcium, at $\mathrm{pH} 9$ and 11.

\begin{tabular}{|c|c|c|c|c|c|c|c|}
\hline \multirow[b]{2}{*}{ pH } & \multirow[b]{2}{*}{$\begin{array}{c}0.01 \mathrm{M} \\
\mathrm{NaCl}\end{array}$} & \multicolumn{3}{|c|}{$0.05 \mathrm{~mol} / \mathrm{L} \mathrm{Mg}$} & \multicolumn{3}{|c|}{$0.05 \mathrm{~mol} / \mathrm{L} \mathrm{Ca}$} \\
\hline & & $\begin{array}{l}\text { No Dis- } \\
\text { persant }\end{array}$ & $\begin{array}{c}100 \mathrm{mg} / \mathrm{L} \\
\text { SHMP }\end{array}$ & $\begin{array}{c}100 \mathrm{mg} / \mathrm{L} \\
\mathrm{SS}\end{array}$ & $\begin{array}{l}\text { No Dis- } \\
\text { persant }\end{array}$ & $\begin{array}{l}100 \mathrm{mg} / \mathrm{L} \\
\mathrm{SHMP}\end{array}$ & $\begin{array}{c}100 \mathrm{mg} / \mathrm{L} \\
\mathrm{SS}\end{array}$ \\
\hline 9 & -29 & -6.1 & -7.5 & -6.3 & -13.2 & -27.1 & -20.5 \\
\hline 11 & -39 & 10.1 & -3.5 & -8.4 & -10.3 & -20.2 & -12 \\
\hline
\end{tabular}

\subsection{Settling Rates}

Figure 8 shows the settling rates of the flotation tailings as a function of dispersant dosages in flotation, at $\mathrm{pH} 9$ and 11 , three flocculant dosages $(8,20,50 \mathrm{~g} / \mathrm{t})$, and different additions of muscovite and biotite. In general, the settling rates increase with the flocculant dosages, and the increase in mica content reduces the positive effect of the flocculant. The experimental data also indicate that the settling rates are reduced as the dispersant dosages in flotation increase in most of the cases.

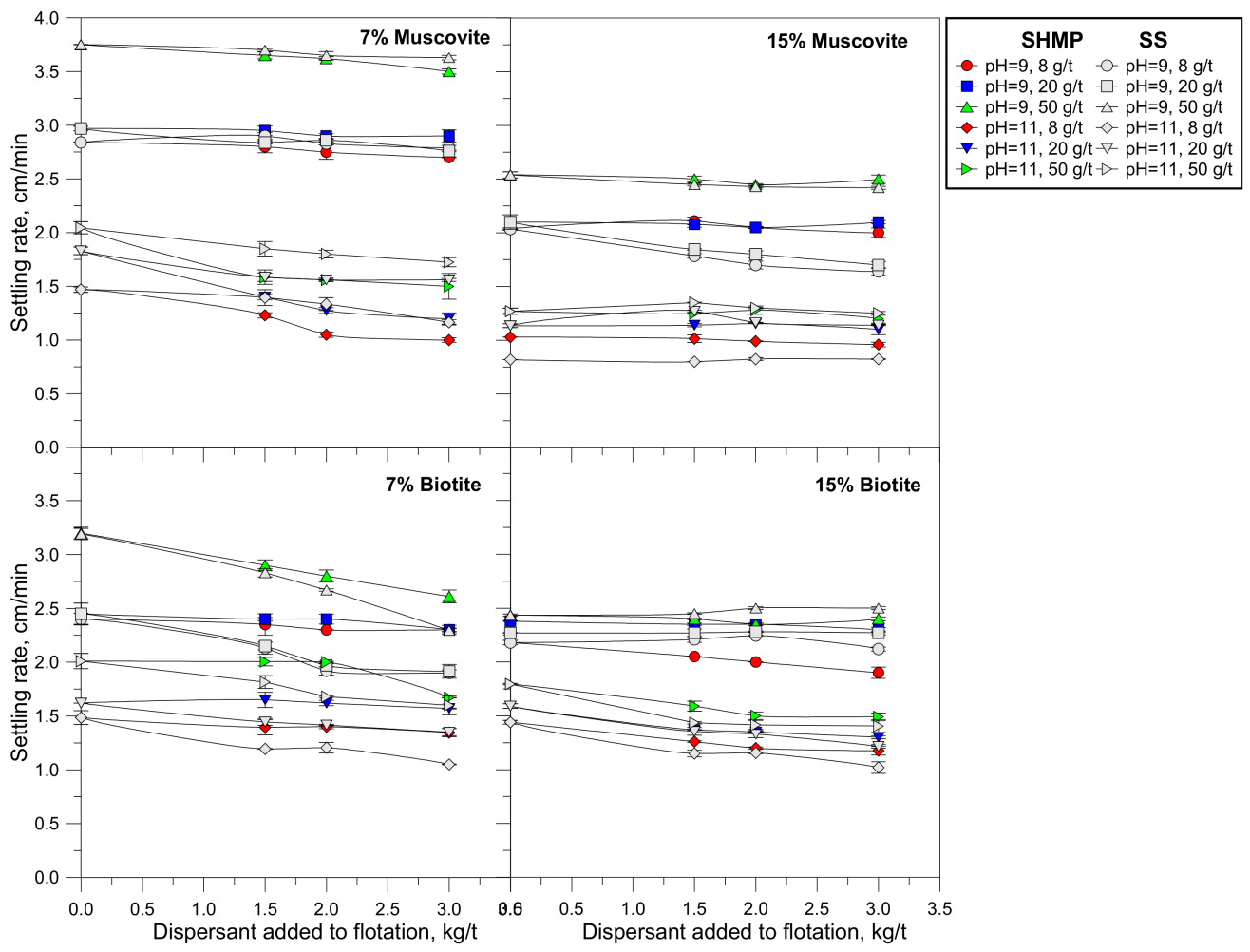

Figure 8. Settling rates of flotation tailings in seawater at $\mathrm{pH} 9$ and 11 as a function of dispersant dosage in flotation (SHMP, SS), and two muscovite and biotite contents. 


\section{Discussion}

Both muscovite and biotite are anisotropic minerals that display varying surface properties on the faces and edges of the mineral particles. Previous studies indicate that these micas' basal planes carry negative charge while the edges carry a charge that depends on $\mathrm{pH}$ [22]. The electrophoretic mobility data obtained in dilute aqueous solutions of calcium and magnesium presented in Figures 6 and 7 indicate that, on average, these mica particles display a negative surface charge. However, these results say nothing about the surface charges on the faces and edges. The results presented in Figure 1 show that the flotation of chalcopyrite and molybdenite in seawater (no micas added) is depressed as $\mathrm{pH}$ changes from 9 to 11 , which agrees with previous results $[8,18]$. Figure 1 also shows that muscovite and biotite depress copper and molybdenum flotation in the process of flotation using seawater and that the depressing effect is more relevant at $\mathrm{pH} 11$ than at $\mathrm{pH}$ 9. The concentrate grades also decrease due to the reduction in flotation of the fully liberated chalcopyrite and molybdenite particles, and the increase in mass pull. The results suggest various mechanisms for the interaction of mica particles with chalcopyrite and molybdenite particles that are outlined in Figure 9 for interactions in (a) fresh water, (b) seawater at $\mathrm{pH} 9$, (c) seawater at $\mathrm{pH} 11$ without micas, and (d) seawater at $\mathrm{pH} 11$ in the presence of micas. As presented in Figure 1, the depressing effect of micas on copper and molybdenum recovery in fresh water $(0.01 \mathrm{M} \mathrm{NaCl}$ solution) is minor, which can be explained by the strong repulsive forces acting between the metal sulfides and mica particles, described in Figure 9a. At pH 9 in seawater (Figure 9b), the depressing effect of micas can be explained by the significant compression of the electrical double layer produced by the high ionic strength of seawater, which was also reported in the case of the study of the depressing effect of kaolinite on chalcopyrite [8]. As a result, heterocoagulation of chalcopyrite/molybdenite with micas is induced, which reduces the hydrophobicity of the metal sulfides and recovery. As seen in Figure 1, at pH 11, seawater also depress the fully liberated particles of chalcopyrite and molybdenite, even in the absence of muscovite and biotite at this alkaline condition, which agrees with results reported in previous studies $[8,17,18]$. The strong depression of copper and molybdenum sulfides originates from the precipitation of hydrophilic magnesium hydroxy-complexes on these minerals through a "slime coating" type mechanism. Such a mechanism reduces chalcopyrite and molybdenite's hydrophobicity, causing low recoveries, as indicated in Figure 9c. Figure 1 also indicates that, at $\mathrm{pH} 11$, a strong depression of chalcopyrite and molybdenite is observed in the presence of micas in seawater. In this condition, the flotation depression is caused by a phenomenon of heterocoagulation between metal sulfide particles and micas caused by the compression of the electrical double layer and by the accumulation of magnesium/calcium precipitates, which induce the attachment of micas on the chalcopyrite and molybdenite surfaces (Figure 9d). In summary, the results presented in Figure 1 agree with previous studies using clay minerals, which report a strong depression of chalcopyrite and molybdenite in the presence of seawater ions $[7,8]$. Hydrolyzed species of calcium and magnesium induce heterocoagulation between slimes and metal sulfides, leading to low recoveries.

SHMP and SS were proposed to remove and disperse hydrophilic precipitates from chalcopyrite and molybdenite surfaces $[8,18]$. The results obtained indicate that these reagents also reduce the depressing effect of micas on the flotation of chalcopyrite and molybdenite in seawater. Figures $2-5$ show that SHMP and SS increase copper and molybdenum recoveries in seawater at $\mathrm{pH} 9$ and 11 to values similar to those obtained without micas. SHMP and SS have a strong binding capacity to alkaline earth metals $[23,24]$. Therefore, they produce an increase in the negative surface charge of the surfaces of the mineral particles, sequestering magnesium and calcium that would otherwise cover the mineral surfaces as colloidal oxide-hydroxide precipitates. The SHMP dissociation reaction is presented in Equation (1). Previous studies show that SHMP modifies the hydroxy complexes of divalent cations $[25,26]$ in agreement with Equations (2) and (3). 


$$
\begin{gathered}
\left(\mathrm{NaPO}_{3}\right)_{6}=\mathrm{Na}_{4} \mathrm{P}_{6} \mathrm{O}_{18}{ }^{2-}+2 \mathrm{Na}^{+} \\
\mathrm{Na}_{4} \mathrm{P}_{6} \mathrm{O}_{18}{ }^{2-}+\mathrm{Ca}^{2+}=\mathrm{CaNa}_{4} \mathrm{P}_{6} \mathrm{O}_{18} \\
\mathrm{Na}_{4} \mathrm{P}_{6} \mathrm{O}_{18}{ }^{2-}+\mathrm{Mg}^{2+}=\mathrm{MgNa}_{4} \mathrm{P}_{6} \mathrm{O}_{18}
\end{gathered}
$$

(a)

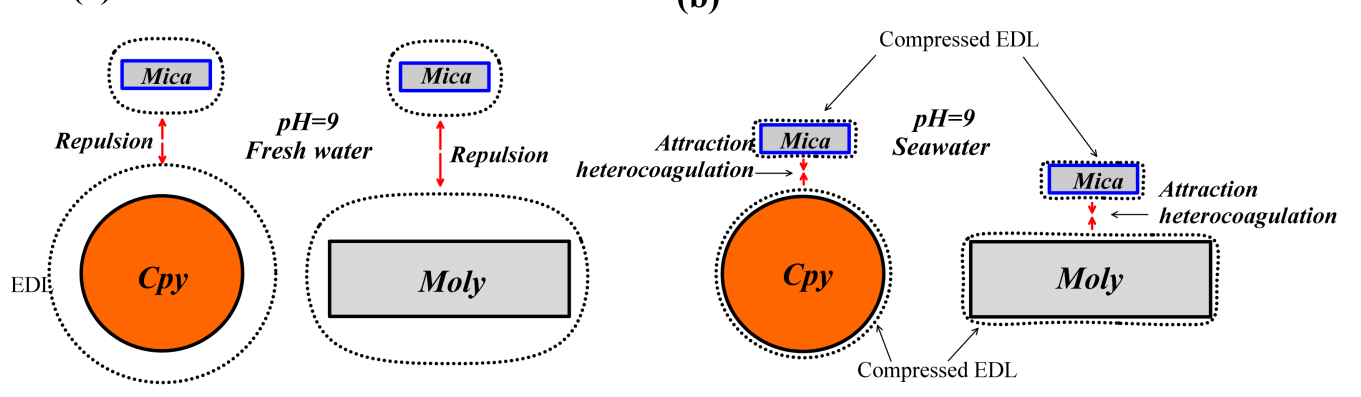

(c)

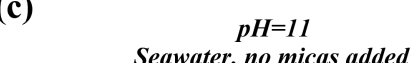

Seawater, no micas added

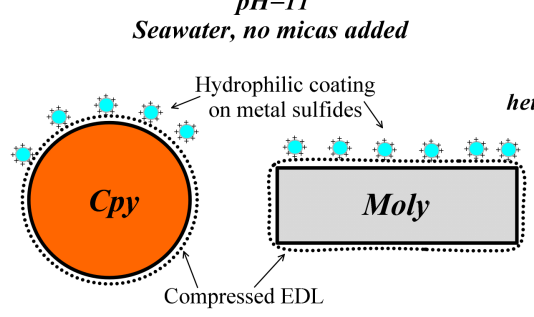

(d)

Hydrophilic coating

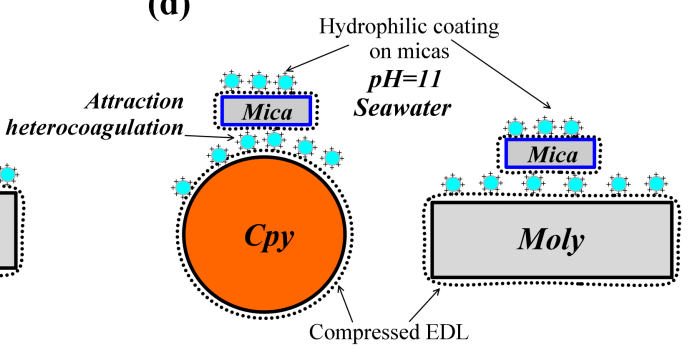

Mg and Ca hydroxy complexes

Figure 9. Suggested mechanisms of interactions between mica particles, and chalcopyrite (Cpy) and molybdenite (Moly) in (a) freshwater, (b) seawater $\mathrm{pH}=9$, (c) seawater $\mathrm{pH}=11$ no micas added, (d) seawater $\mathrm{pH}=11$.

Figure 6 shows that SHMP shifts the electrophoretic mobilities of micas to more negative values, indicating that these reagents interact with and disperse the hydroxy precipitates of magnesium and calcium from the mica surfaces. The data presented in Table 3 show that SHMP switches chalcopyrite's zeta potential to more negative values, particularly at $\mathrm{pH} 11$, which also indicates the dispersion of earth-metal hydroxy precipitates from the chalcopyrite surfaces. These results agree with previous studies [27] of the zeta potential of chalcopyrite in seawater and calcium and magnesium solutions at $\mathrm{pH}$ 10 , that showed that the zeta potentials were positive under these conditions, and that the addition of $50 \mathrm{mg} / \mathrm{L}$ of SHMP switched the surface charge from positive to negative values. Previous studies also showed that the same dispersing effect occurs for molybdenite $[18,28]$. It was demonstrated [18] that SHMP was able to restore molybdenite flotation in the $\mathrm{pH}$ range in which it is depressed by magnesium species and that this dispersant had no effect on pyrite flotation. Other studies [28] found that the surface charge of molybdenite moves to more negative values in the presence of SHMP, indicating that this dispersant removes the positively charged hydrophilic precipitates from the molybdenite surfaces. Therefore, that the surface charge of all the mineral species considered in this study (muscovite, biotite, chalcopyrite, and molybdenite) shifts to more negative values would explain the positive effect of SHMP in the recovery of copper and molybdenum at the $\mathrm{pH}$ of interest here. The results obtained with SS are comparable to those obtained with SHMP. SS $\left(\left(\mathrm{Na}_{2} \mathrm{O}\right)_{x} \bullet\left(\mathrm{SiO}_{2}\right)_{y}\right)$ is a common dispersing agent for slimes, with the $\mathrm{SiO}_{2}$ to $\mathrm{Na}_{2} \mathrm{O}$ ratios generally ranging from 1.6 to 3.75 [29]. It has been suggested that the monomeric species - $\mathrm{Si}(\mathrm{OH})_{4}$ (uncharged), $\left[\mathrm{SiO}\left(\mathrm{OH}_{3}\right)\right]^{-},\left[\mathrm{SiO}_{2}(\mathrm{OH})_{4}\right]^{4-}$, the dimeric species $\left[\mathrm{Si}_{2} \mathrm{O}_{3}(\mathrm{OH})_{4}\right]^{2-}$, and the tetrameric species $\left[\mathrm{Si}_{4} \mathrm{O}_{8}(\mathrm{OH})_{4}\right]^{4-}$ are the most probable silicate components in 
solution [29-31]. Figure 7 shows that SS shifts the electrophoretic mobilities of micas to more negative values, and this effect tends to be more critical at $\mathrm{pH} 11$, which also suggests that SS interacts with and disperses the magnesium and calcium hydroxide complexes from the mineral surfaces. In conclusion, SHMP and SS render the mineral particles more negatively charged by removing the hydroxy complexes of magnesium and calcium from the mineral particles, reducing heterocoagulation between chalcopyrite and molybdenite and mica particles causing higher recoveries.

The improvements in the recovery of metals observed in this work have been explained based on the dispersant's ability to reestablish the hydrophobicity of the metal sulfides lost in the presence of mica. However, it should be considered that the presence of micas in suspension also produces changes in pulp rheology that can also affect flotation. Although, in this work, the maximum solid content of micas by volume was around $2 \%$, and under these conditions, pulp rheology should be only slightly affected, as shown in previous studies [32], more work should be done to determine whether the good performance of the dispersants comes from a change in the surface properties of the mineral particles, from a positive effect on rheology, or both.

The results in Figure 8 show that the settling rates decrease slightly as the doses of the dispersants SHMP and SS added to flotation increase. The addition of dispersants in the flotation stage generates a substantial dispersion of slimes removed from the surfaces of the chalcopyrite and molybdenite particles. Furthermore, at $\mathrm{pH} \mathrm{11,} \mathrm{the} \mathrm{dispersants}$ also remove the magnesium and calcium precipitates from the surface of micas and metal sulfides. These phenomena cause changes in the mass pull, as seen in Figures 3 and 5, which directly influence the presence of fine particles in the flotation tailings; specifically, the higher the mass pull in flotation, the lower the fines that report to tailings. As a result, settling rates should increase. Unfortunately, experimental results show that, independent of the massive tug in flotation, settling rates decrease in the presence of SHMP and SS. The presence of ultrafine particles dispersed by the action of SHMP and SS reagents negatively impact the flocculation and sedimentation processes in the water recovery stage, leading to high consumption of flocculant, low settling rates and high turbidity of the supernatant [33]. Figure 10 shows that turbidity is higher in the presence of dispersants. These latest results should not discourage the use of dispersants, but rather reinforce the need to find better flocculating polymers; in the end, the problem of fines in the mining industry is real with or without dispersants. The computational design of molecules with specific groups offers a possible way forward. It is also important to consider the effect of ions in the aqueous solutions on the molecular conformation of flocculants, which directly influence the settling process efficiency. It was previously proposed that the electric field of the polyacrylamide charged sites is attenuated in ions, which negatively affects the flocculation efficiency [34]. Some mechanisms were proposed to explain the polyacrylamide behavior in solutions containing high concentrations of ions, including charge screening of both anionic particles and flocculant and shielding of the active sites of the flocculant, which causes the polymer to coil [35]. The first mechanism is a precursor of flocculation, while the second is not. The study of the impact of dispersants on the molecular conformation of polyacrylamides in high ionic strength solutions deserves further research. 


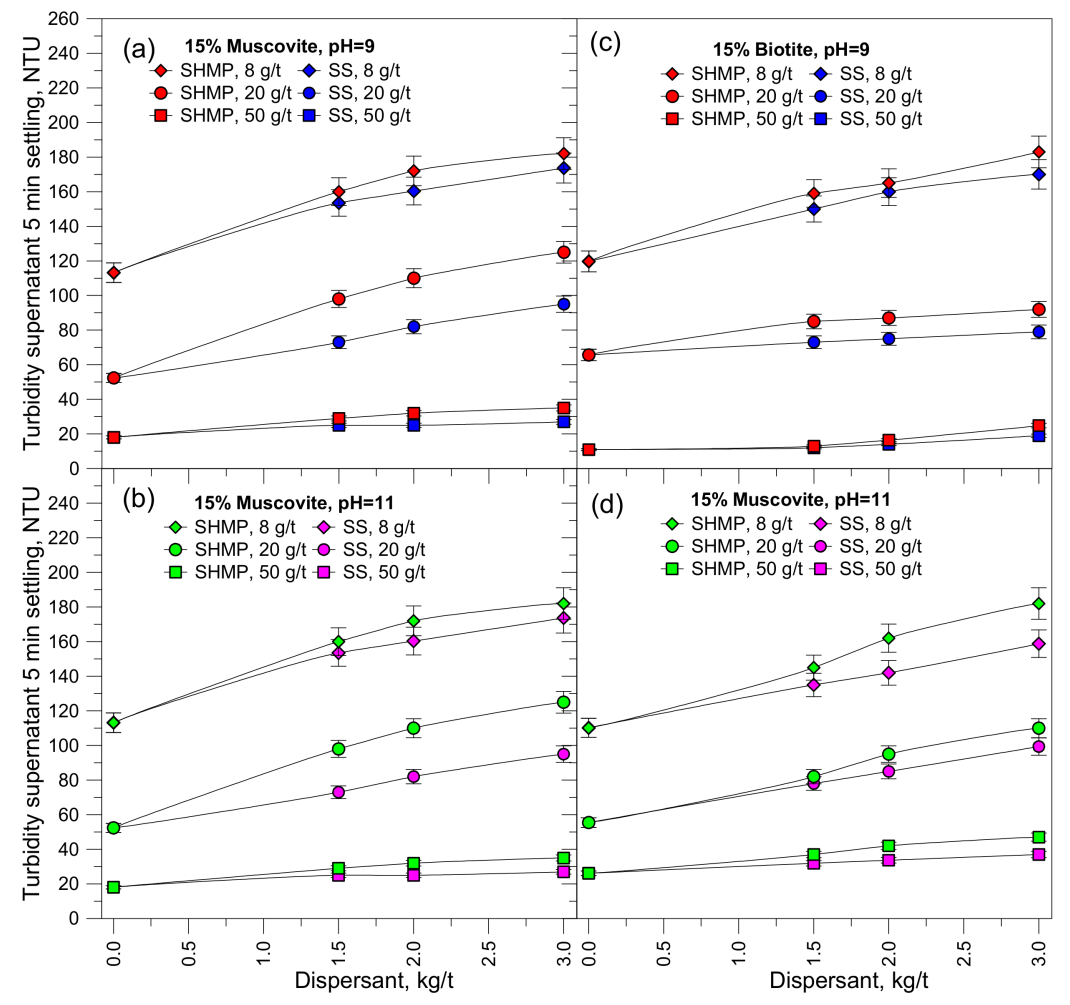

Figure 10. Turbidity of supernatant measured after $5 \mathrm{~min}$ of tailing settling as a function of dispersant additions in the flotation stage.

\section{Conclusions}

Muscovite and biotite micas depress the flotation of chalcopyrite and molybdenite in seawater, this effect being stronger at $\mathrm{pH} 11$ than at $\mathrm{pH} 9$. At $\mathrm{pH} 9$, the effect can be explained by the significant compression of the particles' electric double layer due to the high ionic strength of seawater which induces the heterocoagulation of metal sulfides and slimes. At pH 11, the depression is due to the electrical double layer's compression and the accumulation of magnesium and calcium precipitates that facilitate the union between mica particles and metallic sulfides. Furthermore, hydrolyzed calcium and magnesium species induce hydrophilicity on chalcopyrite and molybdenite surfaces, even in the absence of micas.

Sodium hexametaphosphate and sodium silicate dispersants increase copper and molybdenum recoveries, rendering mineral particles more negatively charged by removing magnesium and calcium hydroxy complexes from mineral particles. As a result, heterocoagulation between chalcopyrite/molybdenite and mica particles is reduced, leading to high recoveries. The surface charge of all the mineral species considered (muscovite, biotite, chalcopyrite, and molybdenite) changes to more negative values in the presence of the inorganic dispersants tested, explaining the positive effect on the recovery of copper and molybdenum in seawater.

Flotation tailings sedimentation rates decrease slightly when sodium hexametaphosphate or sodium silicate is added in the flotation stage. The presence of ultrafine particles dispersed by inorganic dispersants negatively impacts the flocculation and sedimentation processes that lead to a high consumption of flocculant, low settling rates, and high turbidity of the supernatant. Therefore, it is necessary to be careful with dispersants in the flotation process with seawater so that the sedimentation processes are not affected, especially by ultrafine particles. 


\begin{abstract}
Author Contributions: Conceptualization/methodology/investigation/writing-original draft preparation/founding acquisition, R.Y.; Conceptualization/Investigation, J.R.; writing-review and editing/supervision/founding acquisition, P.G.T.; Conceptualization/writing—original draft preparation/writing-review and editing/supervision/ founding acquisition, L.G. All authors have read and agreed to the published version of the manuscript.
\end{abstract}

Funding: This research was founded by ANID/FONDAP/15130015.

Acknowledgments: The authors acknowledge the financial support of the Water Research Centre for Agriculture and Mining (CRHIAM) of the Universidad de Concepción, sponsored the ANID/FONDAP/1530015 project.

Conflicts of Interest: The authors declare no conflict of interest.

\title{
References
}

1. Ramirez, A.; Gutierrez, L.; Laskowski, J.S. Use of oily bubbles and dispersants in flotation of molybdenite in fresh and seawater. Miner. Eng. 2020, 148, 106197. [CrossRef]

2. Forbes, E.; Davey, K.J.; Smith, L. Decoupling rehology and slime coatings effect on the natural flotability of chalcopyrite in a clay-rich flotation pulp. Miner. Eng. 2014, 56, 136-144. [CrossRef]

3. Ndlovu, B.; Farrokhpay, S.; Bradshaw, D. The effect of phyllosilicate minerals on mineral processing industry. Int. J. Miner. Process. 2013, 125, 149-156. [CrossRef]

4. Klein, C.; Hurlbut, C.S. Manual of Mineralogy, 21st ed.; John Wiley and Sons, Inc.: New York, NY, USA, 1993.

5. Kelm, U.; Helle, S.; Jerez, O.; Pincheira, M. What Are Copper Clays? Geometallurgical Implications. In Proceedings of the Copper International Conference, Santiago, Chile, 1-4 December 2013.

6. Uribe, L.; Gutierrez, L.; Jerez, O. The depressing effect of clay minerals on the floatability of chalcopyrite. Min. Proc. Ext. Met. Rev. 2016, 37, 227-235. [CrossRef]

7. Uribe, L.; Gutierrez, L.; Laskowski, J.S.; Castro, S. Role of calcium and magnesium cations in the interactions between kaolinite and chalcopyrite in seawater. Physicochem. Probl. Miner. Process. 2017, 53, 737-749.

8. Ramirez, A.; Rojas, A.; Gutierrez, L.; Laskowski, J.S. Sodium hexametaphosphate and sodium silicate as dispersants to reduce the negative effect of kaolinite on the flotation of chalcopyrite in seawater. Miner. Eng. 2018, 125, 10-14. [CrossRef]

9. Ramirez, A.; Gutierrez, L.; Vega-Garcia, D.; Reyes-Bozo, L. The Depressing Effect of Kaolinite on Molybdenite Flotation in Seawater. Minerals 2020, 10, 578. [CrossRef]

10. McKeown, D.A.; Bell, M.I.; Etz, E.S. Vibrational analysis of the dioctahedral mica: 2M1 muscovite. Am. Min. 1999, 84, 1041-1048. [CrossRef]

11. Maslova, M.V.; Gerasimova, L.G.; Forsling, W. Surface properties of cleaved mica. Colloid J. 2004, 66, 322-328. [CrossRef]

12. Deer, W.A.; Howie, R.A.; Zussman, J. An Introduction to the Rock Forming Minerals, 2nd ed.; Longman Scientific and Technical: New York, NY, USA, 1992.

13. Laskowski, J.S. Role of model systems in fundamental studies on particle-bubble interaction. In Separation Technologies for Minerals, Coal, and Earth Resources, 1st ed.; Luttrell, G., Young, C., Eds.; SME: Englewood, NJ, USA, 2012.

14. Fuerstenau, M.C.; Lopez-Valdivieso, A.; Fuerstenau, D.W. Role of hydrolyzed cations in the natural hydrophobicity of talc. Int. J. Miner. Process. 1988, 23, 161-170. [CrossRef]

15. Castro, S.; Laskowski, J.S. Froth flotation in saline water. KONA Powder Part. J. 2011, 29, 4-15. [CrossRef]

16. Yepsen, R.; Gutierrez, L.; Laskowski, J. Flotation behavior of enargite in the process of flotation using seawater. Miner. Eng. 2019, 142, 105897. [CrossRef]

17. Suyantara, G.P.; Hirajima, T.; Miki, H.; Sasaki, K. Floatability of molybdenite and chalcopyrite in artificial seawater. Miner. Eng. 2018, 115, 117-130. [CrossRef]

18. Rebolledo, E.; Laskowski, J.S.; Gutierrez, L.; Castro, S. Use of dispersants in flotation of molybdenite in seawater. Miner. Eng. 2017, 100, 71-74. [CrossRef]

19. Castro, P.; Huber, M. Chemical and Physical Features of Seawater and the World Ocean. In Marine Biology; McGraw-Hill Higher Education: New York, NY, USA, 2003; pp. 48-71.

20. Li, C.; Somasundaran, P. Reversal of bubble charge in multivalent inorganic salt solutions-Effect of magnesium. J. Colloid Interface Sci. 1991, 146, 215-218. [CrossRef]

21. Quezada, G.R.; Jeldres, M.; Toro, N.; Robles, P.; Toledo, P.G.; Jeldres, R.I. Understanding the flocculation mechanism of quartz and kaolinite with polyacrylamide in seawater: A molecular dynamics approach. Colloids Surf. A 2021, 608, 125576. [CrossRef]

22. Rao, K.H.; Cases, J.M.; Barres, O.; Forssberg, K.S.E. Flotation, electrokinetic and FT-IR studies of mixed anionic/cationic collectors in muscovite-biotite system. In Mineral Processing: Recent Advances and Future Trends; Allied Publishers Limited: New Delhi, India, 1995; pp. 29-44.

23. de Kort, E.; Minor, M.; Snoeren, T.; van Hooijdonk, T.; van der Linden, E. Calcium-biding capacity of organic and inorganic orthoand polyphosphates. Dairy Sci. Technol. 2009, 89, 283-299. [CrossRef] 
24. Vujicic, I.; Batra, S.C.; Deman, J.M. Interaction of alkaline earth ions with polyphosphates and citrate in the presence and absence of casein. J. Agric. Food Chem. 1967, 15, 403-407. [CrossRef]

25. Ma, M. The dispersive effect of sodium hexametaphosphate on kaolinite in saline water. Clays Clay Miner. 2012, 60, 405-410. [CrossRef]

26. Li, W.; Li, Y.; Wei, Z.; Xiao, Q.; Song, S. Fundamental studies of SHMP in reducing negative effects of divalent ions on molybdenite flotation. Minerals 2018, 8, 404. [CrossRef]

27. Li, W.; Li, Y. Improved understanding of chalcopyrite flotation in seawater using sodium hexametaphosphate. Miner. Eng. 2019, 134, 269-274. [CrossRef]

28. Wang, L.; Li, Y.; Fan, R.; Fan, R. Influencing mechanisms of sodium hexametaphosphate on molybdenite flotation using sea water. Physicochem. Probl. Miner. Process. 2019, 55. [CrossRef]

29. Leja, J. Surface Chemistry of Froth Flotation, 1st ed.; Springer Science: New York, NY, USA, 1982.

30. Lagerstrom, G.B. Equilibrium in sodium silicate solutions. Acta Chem. Scand. 1959, 13, 722-736.

31. Ingri, N. Equilibrium Studies of Polyanions. 4. Silicate Ions in NaCl Medium. Acta Chem. Scand. 1959, 13, 758-775. [CrossRef]

32. Ndlovu, B.; Forbes, E.; Farrokhpay, S.; Becker, M.; Bradshaw, D.; Deglon, D. A preliminary rheological classification of phyllosilicate group minerals. Miner. Eng. 2014, 55, 190-200. [CrossRef]

33. Rulyov, N.N.; Dontsova, T.A.; Korolyov, V.J. Ultra-flocculation of diluted fine disperse suspensions. Min. Proc. Extr. Metall. Rev. 2005, 26, 203-217. [CrossRef]

34. Quezada, G.R.; Jeldres, R.I.; Fawell, P.D.; Toledo, P.G. Use of molecular dynamics to study the conformation of an anionic polyelectrolyte in saline medium and its adsorption on a quartz surface. Miner. Eng. 2018, 129, 102-105. [CrossRef]

35. Jeldres, R.I.; Piceros, E.C.; Leiva, W.H.; Toledo, P.G.; Herrera, N. Viscoelasticity and yielding properties of flocculated kaolinite sediments in saline water. Colloids Surf. A Physicochem. Eng. Asp. 2017, 529, 1009-1015. [CrossRef] 